\title{
VULNERABILITY OF THE BIOLOGICAL ELEMENTS OF RIVER BED ECOSYSTEM ON REGULATORY WORKS
}

\author{
Justyna Hachoł', Elżbieta Bondar-Nowakowska' \\ 1 Institute of Environmental Protection and Development, Wrocław University of Environmental and Life \\ Sciences, Plac Grunwaldzki 24, 50-363 Wrocław, Poland, e-mail: justyna.hachol@up.wroc.pl
}

Received: 2016.11.28

Accepted: 2017.01.02 Published: 2017.03.01

\begin{abstract}
The vulnerability of the system to changes is an additional factor that is often taken into account in risk analysis. Usually this assessment takes into account only two elements probability and consequences of an event. The study attempts to assess the vulnerability of vascular aquatic plant communities to the qualitative and quantitative changes as a result of regulatory works in a river bed. The aim of the paper is to assess the possibility of using biological indicators, commonly used in assessing the status of aquatic ecosystems, as indicators of the vulnerability of analyzed communities. These are: the number of plant species, the degree of their bottom coverage, Shannon-Wiener diversity index, Pielou evenness index and ecological status. Field studies were carried out in growing seasons from 2008-2014 in small and medium-sized lowland watercourses in Lower Silesia. The field study included an inventory of vascular aquatic plants. Based on the results of the research, values of biological indicators were calculated and statistical analysis (cluster analysis and Spearman's rank correlation) were performed. On this basis it was found that the number of aquatic plants species and diversity index may be indicators of the vulnerability of plant communities to the changes as a result of river regulation.
\end{abstract}

Keywords: vulnerability, ecological risk, aquatic plants, biodiversity

\section{INTRODUCTION}

Until now, the research has indicated that the result of regulatory works is related to permanent and temporary changes in river bed systems. Alternations refer to vascular aquatic plant communities as well [Fox and Murphy 1990, Lorenz et al. 2012, Bondar-Nowakowska and Hachoł 2015]. During the works plants are removed from the bed and the banks of the watercourse. After their completion plants commence regeneration process. Due to habitat changes in the river bed the process relates to the alternation of plant communities rather than their restoration [Hachoł and Bondar-Nowakowska $2010,2012]$. Because of that regulatory works have to be considered as the reason for the risk of ecological changes in a river bed system. This indicates the need for the formulation of risk management plans as correctly conducted analysis of possible threats and risk assessment constitute the key element in safety management of the river ecosystem.
It is essential to rate the risk while managing it [Pritchard 2001]. Risk rating defines the possibility of the damage occurrence and an assessment of its magnitude. A number of authors includes vulnerability of the system exposed to damage as an additional factor in risk assessment [Peduzzi et al. 2002, Bollin et al. 2003, SchmidtThomé 2006, Wood 2011]. Usually this quantity is calculated in a point-based scale.

Vulnerability of river ecosystems to changes of regulatory works has not been analyzed. This factor is not considered in ecological risk assessment related to regulatory works impact either. Therefore it seems purposeful to conduct such an analysis.

The study aims at an attempt to assess the vulnerability of vascular aquatic plants to changes resulting from regulatory works. Water plants are substantial elements of the river bed system used in an assessment of the ecological condition of the river [European Comission 2000]. The aim of 
the study is to evaluate the possibility of the application of biological metrics (commonly used in characteristics of water plants communities) to assess their vulnerability to qualitative and quantitative changes in the result of regulatory works. The analysis comprises five metrics: the number of vascular aquatic plant species, the degree of the river bed coverage by aquatic plants, Shannon-Wiener diversity index, Pileou evennes index and the class of ecological state of the watercourse defined by water plants.

\section{MATERIAL AND METHODS}

The analysis is based on the field work performed between 2008 and 2014 in ten small and medium lowland Lower Silesian watercourses. In these watercourses 38 study sections were defined (each 100 meters long). Study sections were located in agricultural areas of similar physiographic conditions. Data referring to the watercourses and study sections has been portrayed in Table 1 .

One study section in each watercourse showed natural-like characteristics. During the research no elements of modified river bed due to technical interference have been affirmed therein. It played the reference section role. In further study sections located in adjacent areas of the reference ones or in a short distance from them regulatory works were conducted. Due to the works, all or some of the parameters of longitudinal or cross-section such as: the bottom drop, the depth and width of the river bed, banks inclination were changed. Banks strengthening was conducted using fascine, stone filled wire mesh baskets or concrete elements.

Within the field work in each study section both technical and environmental stocktake was conducted. Technical stocktake included the mea- surement of technical watercourse elements and the assessment of the river bed substrate. Within the environmental stocktake the degree of the river bed shading was assessed with an identification of vascular aquatic plants species and the degree of their coverage of the river bed. All the vascular aquatic plants were taken into account in the study, both rooted for at least $90 \%$ of their vegetation period and free floating on the water surface or beneath it. Water plants species were defined directly in the field. The degree of the bed coverage was assessed using 9 grade scale showed in Table 2 [Szoszkiewicz et al. 2010].

Basing on the obtained data (the number of vascular aquatic plant species and the degree of the river bed coverage by aquatic plants) for each study section both for modified and unmodified Shannon-Wiener diversity index [Schaumburg et al. 2006], Pielou evennes index [Pielou 1974] and the class of environmental state of the river bed were determined [Szoszkiewicz et al. 2010].

To conduct an analysis concerning possibilities of indexes application as measurements of vulnerability of aquatic plant communities to qualitative and quantitative changes in a result of regulatory works differences between their values in reference and corresponding regulated sections were identified. In order to limit the impact on other elements of the river bed system reference sections were divided to homogeneous groups with reference to values of the considered ecological indexes. It was conducted using Ward's cluster analysis . Euclidean distance was taken for distance measure. For the study sections correlation indexes were determined between the values of considered indexes in reference and regulated sections. It is connected with the fact that the changes in aquatic plant communities as a result of regulatory work in the watercourse bed are influenced not only by the range of these works, but

Table 1. Location of the study sections

\begin{tabular}{|c|c|c|c|c|c|}
\hline \multirow{2}{*}{ No. } & \multirow{2}{*}{ Watercourse name } & \multirow{2}{*}{ Mouth } & \multirow{2}{*}{$\begin{array}{c}\text { Watercourse length } \\
{[\mathrm{km}]}\end{array}$} & \multicolumn{2}{|c|}{ Study sections indications } \\
\hline & & & & unmodified & regulated \\
\hline 1 & Czarna Woda & Bystrzyca & 43.8 & 6 & $1,2,3,4,5$ \\
\hline 2 & Dobra & Widawa & 36.1 & 7 & $8,9,10$ \\
\hline 3 & Oleśnica & Widawa & 46.6 & 11 & 12 \\
\hline 4 & Orla & Barycz & 95.1 & 13 & 14 \\
\hline 5 & Potok Sulistrowicki & Czarna Woda & 14.7 & 16 & 15,17 \\
\hline 6 & Sąsiecznica & Barycz & 43.3 & 20 & $18,19,21,22$ \\
\hline 7 & Smortawa & Odra & 39.0 & 24 & $23,25,26$ \\
\hline 8 & Ślęza & Odra & 78.6 & 28 & $27,29,30$ \\
\hline 9 & Żalina & Żurawka & 10.9 & 32 & 31,33 \\
\hline 10 & Żurawka & Ślęza & 28.5 & 35 & $34,36,37,38$ \\
\hline
\end{tabular}


Table 2. Rating scale of the river bed coverage by water plants [Szoszkiewicz et al. 2010]

\begin{tabular}{|c|c|}
\hline River bed coverage index & $\begin{array}{c}\text { Percentile share/ } \\
\text { participation in the coverage }\end{array}$ \\
\hline 1 & $<0.1 \%$ \\
\hline 2 & $0.1-1 \%$ \\
\hline 3 & $1-2.5 \%$ \\
\hline 4 & $2.5-5 \%$ \\
\hline 5 & $5-10 \%$ \\
\hline 6 & $10-25 \%$ \\
\hline 7 & $25-50 \%$ \\
\hline 8 & $50-75 \%$ \\
\hline 9 & $75-100 \%$ \\
\hline
\end{tabular}

also by the qualitative and quantitative condition of aquatic plant communities [Hachol and Bondar-Nowakowska 2016]. Spearman`s rank correlation was used for the analysis. Calculations were conducted for statistical significance of $\alpha=0.05$. All the statistical analyses were conducted with Statistica V.12.5 by StatSoft Polska Sp. z o.o.

\section{RESULTS AND DISCUSSION}

In unmodified sections of the watercourses taken in the research as reference material totally 18 vascular aquatic plants species were identified. The number of species occuring in modified sections as a result of regulatory works was similar -17 species. These values are low in comparison to the values found by authors conducting similar research. Adynkiewicz-Piragas and Drabiński [2001] investigated 23 hundred meter sections of the Smortawa river where 11 aquatic plants species and 29 helophytes species were described. Riis et al. [2008] found 55 aquatic macrophytes taxa in 44 rivers sections with a length of one hundred meters. Caffrey et al. [2006] found 68 aquatic plant species in 90 one hundred meters sections of the rivers. Low number of aquatic plants determined during the field work may be caused by the fact that analyzed watercourses were located in scarcely varied agricultural landscape and all of them were under technical intrusion before.

In unmodified sections of the watercourses taken in the research as reference material the species occurred unequally (Table 3 ). From 2 to 8 species were noted therein. Their coverage of the river bed was also diversified and ranged from 6 to 9 . The performed studies and analyzes demonstrated that the considered values of Shanon-Wiener Index were from 0.47 to 1.91 , while the values of Pielou Index were from 0.23 to 1.0. The results of field studies indicate that the ecological status of watercourse beds in the study sections not subjected to technical interference was in the class from 2 to 4 . Detailed data and values of the calculated biological indexes are included in Table 3 .

Median values of biological indexes in regulated watercourses are included in Table 4. The presented results indicate that the regulatory works affected bed's status described by analysed biological metrics. Their values are generally lower than in the unmodified sections. The data show a decrease in the number of species, lower river bed coverage by aquatic plants, a decrease in values of both Shannon-Wiener and Pielou indexes as well as deterioration in ecological watercourse condition. Only in a few cases a growth or steadiness of the above values can be observed. However, the differences are not large, which may result from a small number of aquatic plant species in unmodified study sections.

The amounts shown in Table 3 indicate inhomogeneity of sections with reference to the occurrence of water plants. Tree diagram accomplished using Ward metod, with euclidean distance amounting to 8 , enabled the division of reference sections to three groups (Fig. 1).

Table 3. Values of biological metrics in unmodified study sections

\begin{tabular}{|c|c|c|c|c|c|c|}
\hline Watercourse name & $\begin{array}{c}\text { Section } \\
\text { specyfication }\end{array}$ & $\begin{array}{c}\text { Number of } \\
\text { species }\end{array}$ & $\begin{array}{c}\text { Bed coverage } \\
\text { degree }\end{array}$ & $\begin{array}{c}\text { Shannon- } \\
\text { Wiener Index }\end{array}$ & $\begin{array}{r}\text { Pielou } \\
\text { Index }\end{array}$ & $\begin{array}{c}\text { Ecological } \\
\text { class }\end{array}$ \\
\hline Czarna Woda & 6 & 5 & 8 & 1.28 & 0.79 & 2 \\
\hline Dobra & 7 & 7 & 9 & 1.32 & 0.68 & 4 \\
\hline Oleśnica & 11 & 5 & 6 & 1.61 & 1.00 & 2 \\
\hline Orla & 13 & 8 & 9 & 0.47 & 0.23 & 4 \\
\hline Potok Sulistrowicki & 16 & 2 & 9 & 0.47 & 0.67 & 4 \\
\hline Sąsiecznica & 20 & 7 & 9 & 1.91 & 0.98 & 2 \\
\hline Smortawa & 24 & 7 & 8 & 1.67 & 0.86 & 2 \\
\hline Ślęza & 28 & 4 & 6 & 1.39 & 1.00 & 2 \\
\hline Żalina & 32 & 3 & 9 & 1.01 & 0.92 & 4 \\
\hline Żurawka & 35 & 4 & 9 & 0.61 & 0.44 & 4 \\
\hline
\end{tabular}


Table 4. Median values of biological metrics in regulated study sections

\begin{tabular}{|l|c|c|c|c|c|c|}
\hline Watercourse name & $\begin{array}{c}\text { Sections } \\
\text { specyfication }\end{array}$ & $\begin{array}{c}\text { Number of } \\
\text { species }\end{array}$ & $\begin{array}{c}\text { Bed coverage } \\
\text { degree }\end{array}$ & $\begin{array}{c}\text { Shannon- } \\
\text { Wiener Index }\end{array}$ & $\begin{array}{c}\text { Pielou } \\
\text { Index }\end{array}$ & $\begin{array}{c}\text { Ecological } \\
\text { class }\end{array}$ \\
\hline Czarna Woda & $1,2,3,4,5$ & 5 & 8 & 1.39 & 0.73 & 3 \\
\hline Dobra & $8,9,10$ & 3 & 8 & 0.30 & 0.21 & 4 \\
\hline Oleśnica & 12 & 1 & 2 & 0.00 & 0.00 & 5 \\
\hline Orla & 14 & 5 & 6 & 1.19 & 0.74 & 3 \\
\hline Potok Sulistrowicki & 15,17 & 2 & 3 & 0.42 & 0.61 & 4 \\
\hline Sąsiecznica & $18,19,21,22$ & 2 & 5 & 0.73 & 0.77 & 3 \\
\hline Smortawa & $23,25,26$ & 4 & 5 & 1.00 & 0.72 & 3 \\
\hline Ślęza & $27,29,30$ & 1 & 2 & 0.00 & 0.00 & 5 \\
\hline Żalina & 31,33 & 4 & 6 & 1.07 & 0.88 & 4 \\
\hline Żurawka & $34,36,37,38$ & 2 & 5 & 0.33 & 0.47 & 5 \\
\hline
\end{tabular}

The first cluster comprises of three watercourse sections $(6,11,28)$ where $4-5$ species were found and their bed coverage according to a 9 grade scale ranged from 6 to 8 . The second group included sections $(16,32,35)$ with 2 to 4 aquatic plants species. These plants covered above $75 \%$ of the bed area (grade 9). The third cluster comprises the following sections:. 7, 13, 20, 24. In these sections 7-8 species were identified. Water plants covered the river bed in 8 and 9 grade.

Taking into account the depicted classification of reference sections each group was attributed with corresponding regulated sections. Subsequently, the values of the considered indexes in these sections were compared with unmodified ones. Differences in the values of particular indexes obtained basing on comparisons are presented in Figure 2.

Data depicted in Fig. 2 indicates that in most regulated study sections the values of analysed biological metrics decreased. In the study sections in groups 1 and 2 there was a loss of aver- age species. In $1^{\text {st }}$ group there are study sections where the number of species increased by 2 and also the sections where the number decreased by 4 species. In the second group the range of changes in the number of aquatic plant species is smaller, with values ranging from +1 to -3 . Major changes are observed in group 3. In those study sections there is a loss of average 3 species. The changes vary in the range from +2 to -6 species. All the regulated sections show lower river bed coverage by aquatic plants. In all regulated sections the average values of both Shannon-Wiener and Pielou indexes decreased. The smallest range of changes occurs in group 2, the largest range in group 3. The results of the field studies indicate that the ecological status of watercourse beds in the most study sections where the regulatory works were performed deteriorated. In groups 1 and 3 the range of the changes vary from +1 to -3 classes. In group 2 the changes in ecological status in comparison to unmodified sections range from +1 to -1 class.

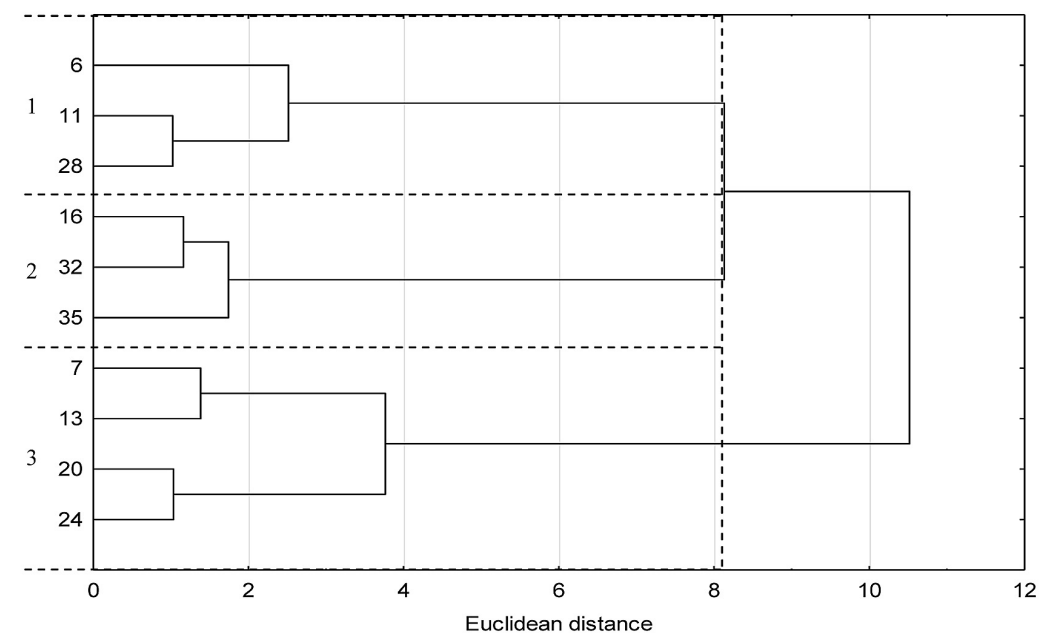

Figure 1. Classification of unmodified study sections into homogeneous groups with respect to the values of analyzed ecological indicators basing on cluster analysis 


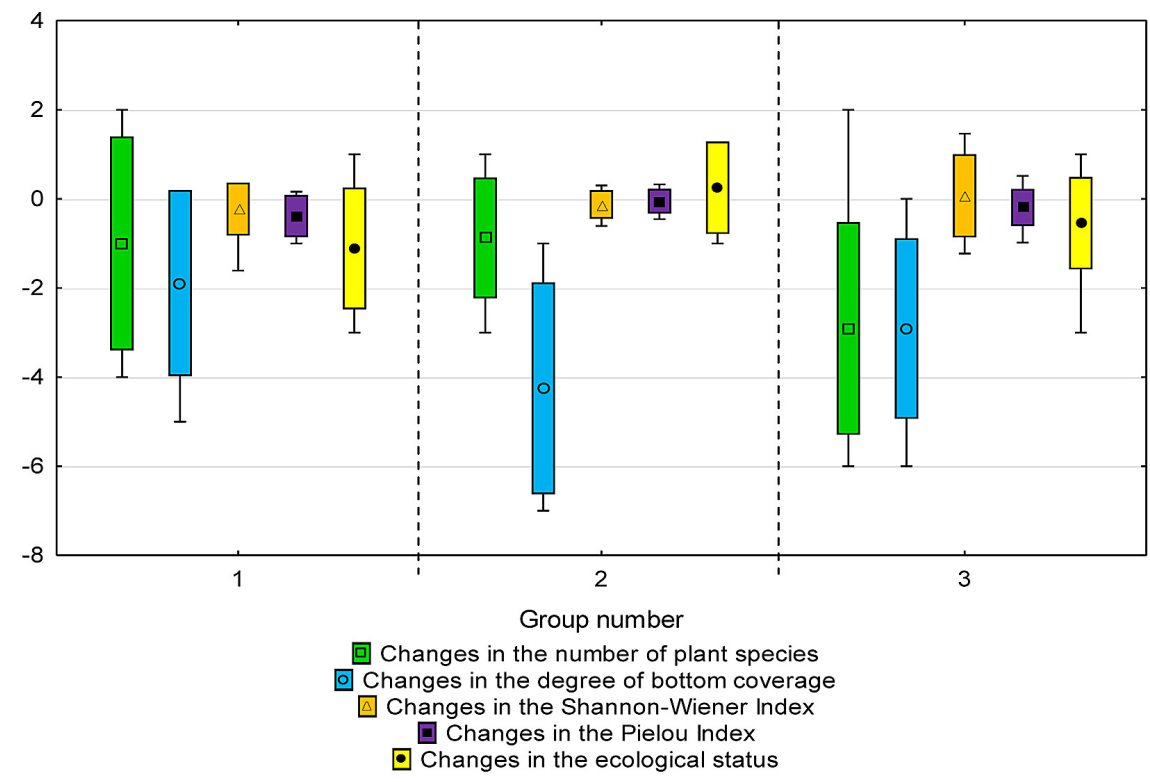

Figure 2. Differences in biological indexes values in regulated and non-regulated river sections

In order to assess if the changes of particular indexes in regulated sections showed any reference to plants condition present in nonregulated sections Spearman ranks coefficients were calculated. The values were presented in Table 5. Marked correlation coefficients are significant with $\mathrm{p}<0.05$.

The data showed in Table 5 indicate that the biggest reference to changes in ecological indexes in the result of works is observed in ShannonWiener and Pielou Indexes in unmodified sections. Even though the marked values of Spearman rank coefficients suggest average correlations, they concern only particular indexes (Pielou Index and Ecological state in regulated study sections). The research does not indicate a distinct relation to species or quantitative state in natural river bed and changes of this state in modified watercourses. It might result from a small number of aquatic plant species in unmodified sections. Therefore, at current phase of the research biological indexes, such as: the number of vascular aquatic plants, a degree of their coverage of the river bed, Shannon-Wie- ner diversity index, evennes Pielou index and the grade of ecological state of a watercourse cannot be used in ecological risk assessment as the measure of aquatic plants vulnerability to regulatory works. It might result from the complexity of the watercourse system [Caffrey et al. 2006, Page et al. 2012] where the vulnerability to disabilities depends on many factors such as: the size of the ecosystem, its fragmentation, the degree of foregoing modification of the watercourse, the use method of the littoral zone, quantitative and qualitative composition of plant and animal communities and individual species reaction [Hill et al. 2001, Caffrey et al. 2006, Camporeale et al. 2013, Hachoł and Bondar-Nowakowska 2016].

\section{CONCLUSIONS}

The conducted research indicated that regulatory works including alternations in technical parameters of the watercourse and banks protection influence quantitative and qualitative compo-

Table 5. Spearman ranks coefficients between ecological indexes in unmodified sections and the magnitude of their changes in regulated sections

\begin{tabular}{|c|c|c|c|c|c|}
\hline \multirow{2}{*}{$\begin{array}{l}\text { Indexes values in } \\
\text { unmodified sections }\end{array}$} & \multicolumn{5}{|c|}{ Changes of ecological indexes values in modified sections } \\
\hline & $\begin{array}{l}\text { Number of } \\
\text { species }\end{array}$ & $\begin{array}{c}\text { Bed coverage } \\
\text { degree }\end{array}$ & $\begin{array}{l}\text { Shannon-Wiener } \\
\text { Index }\end{array}$ & Pielou Index & Ecological state \\
\hline Number of species & -0.303 & 0.020 & 0.173 & 0.052 & -0.039 \\
\hline Bed coverage degree & -0.151 & -0.305 & -0.081 & 0.318 & 0.341 \\
\hline Shannon-Wiener Index & -0.366 & 0.092 & 0.067 & -0.442 & -0.459 \\
\hline Pielou Index & -0.116 & 0.011 & 0.006 & -0.512 & -0.526 \\
\hline Ecological state & 0.005 & -0.273 & -0.205 & 0.313 & 0.465 \\
\hline
\end{tabular}


sition of aquatic plant communities. The impact measure is the change in indexes values depicting communities in regulated sections. Due to the lack of strong correlation with plants in unmodified watercourse on the current phase of the research water plants vulnerability to regulatory works is impossible to define.

Shannon-Wiener and Pielou indexes may become water plants vulnerability indexes to regulatory works. However, it requires further research and analyses.

The most threatened with disabilities elements of analyzed system should constitute indicating elements. In case of regulatory works aquatic plant communities present in the watercourse should be regarded as such. The lack of relation between their quantitative and qualitative composition conveyed by values of basic ecological indexes and the magnitude of alternations in these indexes in result of regulatory works may indicate the need of analyzing further individual reactions of particular water plant species.

\section{REFERENCES}

1. Adynkiewicz-Piragas M., Drabiński A. 2001. Wpływ inwestycji hydrotechnicznych na ekosystem rzeki Smortawy. Zeszyty Naukowe AR we Wrocławiu, 417, 7-28.

2. Bollin C., Cárdenas C., Hahn H., Krishna Vats S. 2003. Disaster Risk Management by Communities and Local Governments, DC: Inter-American Development Bank, Washington.

3. Bondar-Nowakowska E., Hachoł J. 2015. Ecological risk assessment in the regulated watercourses. Journal of Ecological Engineering, 16(5), 182-188.

4. Caffrey J.M., Monahan C., Tierney D. 2006. Factors influencing the distribution of aquatic plant communities in Irish canals. Hydrobiologia, 570, 133-139.

5. Camporeale C., Perucca E., Ridolfi L., Gurnell A.M. 2013. Modeling the interactions between river morphodynamics and riparian vegetation. Rev Geophys, 51(3), 379-414.

6. European Commission. 2000. Directive 2000/60/ EC. Establishing a framework for community action in the field of water policy. European Commission PE-CONS 3639/1/100 Rev 1, Luxemburg.

7. Fox A.M., Murphy K.J. 1990. The efficacy and ecological impacts of herbicide and cutting regimes on the submerged plant communities of four British rivers II. A multivariate analysis of the effect of management regimes on macrophyte communities. Journal of Applied Ecology, 27, 541-548.

8. Hachoł J., Bondar-Nowakowska E. 2010. Effect of regulation and maintenace works on aquatic plant communities in the Dobra, Żalina and Żurawka rivers (in Polish). Zeszyty Problemowe Postępów Nauk Rolniczych, 548, 157-165.

9. Hachoł J., Bondar-Nowakowska E. 2012. Tendencies in the development of hydromacrophytes after the completion of regulatory and maintenance works in a river bed. Ecological Chemistry and Engineering A, 19, 997-1013.

10. Hachoł J., Bondar-Nowakowska E. 2016). Aquatic plants-based risk model for assessment of ecological safety of rivers. Human and Ecological Risk Assessment: An International Journal, 22(4), 1065-1077.

11. Hill W.R., Mulholland P.J., Marzolf E.R. 2001. Stream ecosystem responses to forest leaf emergence in spring. Ecology, 82, 2306-2319.

12. Lorenz A.W., Korte T., Sundermann A., Januschke K., Haase P. 2012. Macrophytes respond to reachscale river restorations. Journal of Applied Ecology, 49, 202-212.

13. Page T., Heathwaite A.L., Moss B., et al. 2012. Managing the impacts of nutrient enrichment on river systems: dealing with complex uncertainties in risk analyses. Freshwater Biology, 57, 108-123.

14. Peduzzi P., Dao H., Herold C. 2002. Global Risk And Vulnerability Index. Trends per Year (GRAVITY). Phase II: Development, analysis and results. United Nations Development Programme. Bureau of Crisis Prevention \& Recovery (UNDP/BCPR), Geneva.

15. Pielou E.C. 1974. Population and community ecology: principles and methods. Gordon and Breach, New York.

16. Pritchard C.L. 2001. Risk Management-Concepts and Guidance. ESI International, Virginia.

17. Riis T., Suren A.M., Clausen B., Sand-Jensen K. 2008. Vegetation and flow regime in lowland streams. Freshwater Biology, 53, 1531-1543.

18. Schaumburg J., Schranz C., Stelzer D., Hofmann G., Gutowski A., Foerster J. 2006. Instruction Protocol for the ecological Assessment of Running Waters for Implementation of the EC Water Framework Directive: Macrophytes and Phytobenthos. Bavarian Environment Agency, München.

19. Schmidt-Thomé P. 2006. ESPON Project 1.3.1 Natural and technological hazards and risks affecting the spatial development of European regions. Geological Survey of Finland.

20. Szoszkiewicz K., Jusik, S., Zbierska, J., Zgoła, T. 2010. Makrofitowa Metoda Oceny Rzek. Podręcznik metodyczny do oceny i klasyfikacji stanu ekologicznego wód płynących w oparciu o rośliny wodne. Bogucki Wydawnictwo Naukowe, Poznań.

21. Wood N. 2007. Variations in community exposure and sensitivity to tsunami hazards in Oregon: Reston, Va., USGS Scientific Investigations Report. 